\title{
Introducing a reward system in assessment in histology: A comment on the learning strategies it might engender Michelle McLean
}

Address: Department of Physiology Faculty of Medicine, University of Natal, Private Bag 7 Congella 4013, South Africa

E-mail:mcleanm@nu.ac.za

Published: 26 November 2001

BMC Medical Education 2001, I:7
Received: 15 October 2001

Accepted: 26 November 2001

This article is available from: http://www.biomedcentral.com/1472-6920/1/7

(C) 200 I McLean; licensee BioMed Central Ltd. Verbatim copying and redistribution of this article are permitted in any medium for any non-commercial purpose, provided this notice is preserved along with the article's original URL. For commercial use, contact info@biomedcentral.com

\begin{abstract}
Background: Assessment, as an inextricable component of the curriculum, is an important factor influencing student approaches to learning. If assessment is to drive learning, then it must assess the desired outcomes. In an effort to alleviate some of the anxiety associated with a traditional discipline-based second year of medical studies, a bonus system was introduced into the Histology assessment. Students obtaining a year mark of $70 \%$ were rewarded with full marks for some tests, resulting in many requiring only a few percentage points in the final examination to pass Histology.
\end{abstract}

Methods: In order to ascertain whether this bonus system might be impacting positively on student learning, thirty-two second year medical students (non-randomly selected, representing four academic groups based on their mid-year results) were interviewed in 1997 and, in 1999, the entire second year class completed a questionnaire $(n=189)$. Both groups were asked their opinions of the bonus system.

Results: Both groups overwhelming voted in favour of the bonus system, despite less than $45 \%$ of students failing to achieve it. Students commented that it relieved some of the stress of the yearend examinations, and was generally motivating with regard to their work commitment.

Conclusions: Being satisfied with how and what we assess in Histology, we are of the opinion that this reward system may contribute to engendering appropriate learning approaches (i.e. for understanding) in students. As a result of its apparent positive influence on learning and attitudes towards learning, this bonus system will continue to operate until the traditional programme is phased out. It is hoped that other educators, believing that their assessment is a reflection of the intended outcomes, might recognise merit in rewarding students for consistent achievement.

\section{Background}

There are several reasons traditionally quoted to defend our need to assess student performance. Some relate to the students (formative assessment; evaluation of teaching/learning strategies), others to the institution (summative assessment; quality assurance), while other reasons relate to society (accountability; employment criteria). Since assessment is currently an unavoidable component of any teaching programme, it is imperative that we take cognisance of how we assess and what we assess. We must not allow assessment to drive the learning unless we are sure that it is a true reflection of our intended outcomes with regard to student learning $[1,2]$.

The learning approaches that students adopt are dependent on several factors, including the personal traits 
Table I: Characteristics of the surface, deep and strategic approaches to learning (adapted from Entwistle, 1997; p. I9).

DEEP APPROACH (Transformative)

Intention - to understand ideas for oneself by

- Relating ideas to previous knowledge and experience

- Looking for patterns and underlying principles

- Examining logic and argument carefully and critically

- Checking evidence and relating it to conclusions

- Becoming intrinsically interested in the subject material

SURFACE APPROACH (Reproductive)

Intention - to cope with course requirements by

- Memorising facts and procedures

- Approaching course contents as discrete bits of information

- Studying without reflecting on purpose or strategy

- Feeling undue pressure, stress and worry about work

- Experiencing difficulty in making sense of new ideas presented

STRATEGIC APPROACH (Organisational)

Intention - to achieve the highest possible marks by

- Putting constant effort into studying

- Managing time and effort effectively

- Finding the right conditions and materials for studying

- Gearing work to the perceived preferences of staff members

- Being alert to assessment requirements and criteria, seeking cues

of the student, the teaching attributes of the faculty as well as the characteristics of the department in which students find themselves and the curriculum (including assessment) [3-6]. In response to these influences, students may become surface, deep or strategic learners $[3,7,8]$ (Table 1). Assessment and volume overload are regarded as two of the major factors influencing approaches to learning $[3,4,9,10]$. Student conceptions of learning (i.e. reproductive or transformative), according to Marton et al. (1993), might also impact on the approaches students adopt with regard to learning, ultimately impacting on academic achievement $[11,12]$.

The type and frequency of assessment is thus likely to influence the calibre of learners we produce. To this end, if assessment is largely in the form of multiple choice questions, testing volumes of factual knowledge, then even those students who are usually deep learners may be forced to become surface learners [3]. Furthermore, if there are too many tests, giving students little time to reflect on what they are doing between the tests, the end result is the same - to the detriment of the student. In the traditional medical curriculum, where the basic and clinical sciences are separated and subjects taught within disciplines, students are more often than not tested in the same fashion - discipline-based, with little horizontal or vertical integration. The net result is that most students are forced to spend hours learning facts, often without any application and without understanding the relevance of what they are studying. Since the deep learner is able to understand the subject material, is usually capable of independent study and is intrinsically motivated to study, it should be the desire of each institution, department and educator to promote students to develop such an approach to learning. It is imperative therefore that assessment is congruent with these outcomes as the onus for engendering more transformative conceptions of learning (involving reflection and self-development) rests to a large extent with the educators.

If assessment is to be truly integrated into the curriculum, then we need to ensure that it positively impacts on student learning. For many years, educators have been talking about educational or "authentic" assessment, in which the tasks we set students mirror the learning outcomes expected of them $[1,13]$. In medical practice, doctors are faced with patients who present with problems, requiring knowledge to be accessed in a particular fashion (as well as skills and attitudes). As students, it is therefore essential that they face the same patient-based scenarios that they will encounter in medical practice. In more innovative curricula such as case-based medicine or problem-based learning, several institutions have thus expended considerable effort on developing more appropriate or authentic assessment methods which measure expected outcomes (i.e. problem-solving and critical reasoning skills). In traditional discipline-based curricula, the task of 'authentic' assessment is perhaps more challenging, because, with the clinical/preclinical divide, students might not appreciate the relevance of the basic medical sciences in the context of medicine.

Since assessment is an inextricable part of the curriculum, students also need to view it as a positive influence on their learning. The present investigation reports on the sentiments of two cohorts of second year medical students with regard to a reward system operating in the Histology course in a volume overloaded traditional curriculum in which students write approximately 32 tests in as many weeks. Recognising the shortcomings of the traditional curriculum, the medical programme has been revised, and a more student-centred curriculum (problem-based learning) was implemented in January 2001. Student comments with regard to the reward system in the traditional Histology course are discussed in the light of the approaches to learning they might adopt in response to this incentive, taking into consideration the definitions of surface, strategic and deep learner $[3,8]$. 


\section{Methods}

The institution and the students

The Nelson R. Mandela School of Medicine (University of Natal, Durban, South Africa) was established in 1950 and has been responsible for training Black (historically includes Africans, Indians and Coloureds) for the past 50 years. In 1996, the Faculty adopted an open admission policy, such that students are admitted into the Faculty according to demographics and academic achievement. In the traditional curriculum that is currently being phased out with the implementation of a problem-based learning curriculum in January 2001 (Year 1), students studied basic science and preclinical medical subjects in the first three years, with each discipline being responsible for overseeing its assessment.

\section{Assessment in Year 2 of the traditional curriculum at the Nelson R. Mandela School of Medicine}

In the traditional curriculum at the Nelson R. Mandela School of Medicine, students in the second year of their studies have frequently complained about volume overload and the large number of tests they have to write, both of which will undoubtedly contribute to high levels of stress amongst students $[12,14]$. During this year, students are expected to undertake year-end examinations in Histology (theory and practical). Biochemistry (theory and applied combined). Physiology (theory and applied) and Anatomy (theory, spotter and viva). In addition, some students are selected to participate in a viva in which they might be tested on Histology, Biochemistry and Physiology. For all courses, the year (class) mark comprises $50 \%$ of the total mark, with the remaining $50 \%$ being contributed by the year-end examinations.

In Histology, the emphasis of the course is on the practical aspect, where students are encouraged to relate structure to function. During the year, the systems of the body are studied within units (modules). For assessment purposes, students undertake four non-revision unit competence tests (UCT) and two revision UCTs, one at midyear and one towards the end of the year. Tests comprise largely ( \pm two-thirds) tissue identification (including applied questions such as function, relationship to other structures, etc.), reflecting the emphasis on the type of learning in which we expect students to engage. Students therefore need to integrate their Physiology and Biochemistry with Histology, and are advised from the outset that they should not study Histology in isolation. The theory component of the UCT is assessed either as TRUE/FALSE questions (non-revision UCTs) or as multiple choice questions (MCQs), the latter combined with a short written component in the revision UCT. For the practical component, students are shown $35 \mathrm{~mm}$ slides and asked questions relating to the projected histological image. Since the practical component comprises $\pm 60 \%$ of a UCT, it is extremely difficult to pass without being able to identify the tissues and relate structure to function. At the end of the year, prior to the final examinations, student marks for all UCTs are calculated. If a student obtains an average mark of $70 \%$ and above for all six tests combined, a bonus system operates. In this scheme, full marks are awarded for the non-revision tests (72/72). The mark obtained for the two revision tests (x/50), however, remains. For a student obtaining the bonus, this reward system means that he/she often needs only obtain a few percentage points in the yearend examination to pass the Histology course. For students not achieving 70\%, the actual mark obtained for each test during the year counts.

\section{The study}

After implementing the bonus system in Histology for several years, it was necessary to gauge student opinions of its value and reflect on the type of learning it might be promoting, based on student comments.

\section{7 students}

Two groups of second year medical students were canvassed. In 1997, thirty-two students were non-randomly selected according to their mid-year results in Histology and Biochemistry + Physiology such that they represented four academic groups (<50\%; 50-59\%; 60-69\%; $\geq 70 \%$ ) based on their overall performance. Individual students were interviewed extensively ( \pm 45 minutes) about various aspects of their experiences and perceptions of the first two years of medical studies [12]. One aspect was an evaluation of the Histology course, including the assessment methods and the bonus system. Students were asked whether they thought that the bonus system was a good idea (YES/NO), and asked to explain their answer, irrespective of their response. Their comments were recorded by the author, who was also the interviewer.

\section{9 students}

A second group of students completed a questionnaire at the end of their final Histology examination in 1999 ( $n=$ 189 of 192 students; $98.4 \%$ ). As with the interviews conducted in 1997, students were probed with respect to various aspects of their experiences in the second year of study, including their view of the bonus system in Histology.

\section{Analysis of student comments}

In order not to introduce personal bias or to lose the essence of student sentiments, the comments were grouped with minimal interference from the author. For example, the author views "work harder " and "work consistently " differently (i.e. more effort in general vs. more consistent effort). 


\section{Results}

Table 2 would indicate that both groups of students voted overwhelming (97\% and 89\%) in favour of the reward system, despite only $41 \%$ and $43 \%$ of students obtaining the bonus in 1997 and 1999, respectively. According to the students, the main reasons given for the positive response to this system were that it made them work harder and consistently, and the extra marks earned eased some of the pressure and stress associated with the yearend examinations (Tables 3 and 4). Some student comments suggest that they may have benefited pedagogically from the incentive - gave a better understanding of the subject, made them always want to do their best, prevented cramming and gave them confidence to face the year-end examinations. Others saw the strategic value of obtaining these extra marks - it boosted their overall class mark (which reflects the Physiology, Histology and Biochemistry marks combined). By achieving higher marks for Histology, they could concentrate on the other subjects they had to undertake at the end of the year (Biochemistry, Physiology and Anatomy).

Table 2: Student responses to the value of the bonus system in Histology.

\begin{tabular}{lc}
\hline 1997 STUDENTS $(\boldsymbol{n}=\mathbf{3 2})$ : & \\
IS THE BONUS SYSTEM GOOD? & YES, $97 \%$ \\
STUDENTS ACHIEVING A BONUS & $41 \%$ \\
\end{tabular}

\section{STUDENTS ( $n=189)$ :}

IS THE BONUS SYSTEM MOTIVATING? STUDENTS ACHIEVING A BONUS

YES,89\% $43 \%$

Despite a number of students not obtaining the bonus, or perhaps falling marginally short of the $70 \%$, which some intimated was disappointing, many nonetheless admitted that $70 \%$ was an attainable goal in which understanding and consistent effort are rewarded (Tables 3 and 4). Interestingly, one student believed the exact opposite - a mark of $70 \%$ was too low, making students complacent about achieving good scores. According to this student, his colleagues should be aiming for higher marks. This student was presumably one of the high achievers and did not consider that some students, for one or other reason, may have been struggling with the course. Those students who indicated that the bonus system was not motivating, either did not give an appropriate reason or felt that a $70 \%$ average was beyond their personal reach and perhaps concentrated their efforts elsewhere (Table 4).

Table 3: Student ( 1997 ) comments regarding the positive and negative aspects of the bonus system in Histology.

1997 students
Individual comments*
$(n=32)$

\section{Positive}

Relieves stress/pressure of final exam $\quad 67 \%$

Prevents cramming/Promotes continuous work $\quad 37 \%$

Reward/incentive/motivation to work hard 15\%

Something to strive towards $\quad 9 \%$

Boosts self-confidence $3 \%$

Get marks before exam $\quad 3 \%$

\section{Negative}

Perception that it disadvantages some $3 \%$

*Students may have made more than one comment

Table 4: Student (1999) reasons for the Histology reward system being motivating or non-motivating.

\begin{tabular}{ll}
\hline Individual comments & \% students \\
$(n=188)$
\end{tabular}

$\begin{array}{lc}\text { Reasons for bonus being motivating } & (\boldsymbol{n}=\mathbf{1 6 8}) \\ \text { Reward/incentive } & 61 \% \\ \text { Incentive/reward to work harder/put more effort in } & 47 \% \\ \text { Sets a high standard to achieve your best/a challenge } & 11 \% \\ \text { A goal (attainable)/everyone wants to get it } & 3 \% \\ \text { Less pressure at the end of year } & 34 \% \\ \text { Encouraged consistent work/prevents cramming } & 21 \% \\ \text { Less pressure/stress/anxiety at the end } & 10 \% \\ \text { Kept me focused, on my toes } & 3 \% \\ \text { Relating to Histology } & 2.4 \% \\ \text { e.g. know where you stand with Histology knowledge; } & \\ \text { gave me a better understanding of Histology } & \\ \text { Other benefits } & 6 \% \\ \text { Could pay more attention to other courses } & 2 \% \\ \text { Boosted overall Physiology mark/year mark } & 2 \% \\ \text { Gave me hope/confidence for the final exam } & 2 \% \\ \text { Yes, but 70\% a bit low } & <1 \% \\ \end{array}$

\section{Reasons for bonus not being motivating}

Didn't get it (not a reason!)

$(n=20)^{*}$

Difficult to obtain

Other reasons

$10 \%$

e.g. Already set myself a target mark; did not want to

$4 \%$

focus on Histology; had an academic problem, etc.

Makes people complacent - should aim for $>70 \%$

$<1 \%$ 


\section{Discussion}

In a curriculum overloaded with content volume and almost a test a week ( 32 per year, excluding the end of year examinations), second year medical students at the University of Natal have very little time for any other activities, let alone reflect on the significance of what they were learning. Student responses to the interview questions and the questionnaire items would suggest that stress, inappropriate learning strategies and volume overload were all difficulties they had or were facing during their second year [12], confirming the results of a previous study involving medical students from this Institute [14]. As educators in Histology, we were therefore faced with the responsibility of attempting to remedy the situation within the constraints of the system and the traditional curriculum. By introducing a reward system for consistent progress in Histology during the year, we believed that this would promote continuous student effort, effectively reducing the emphasis on the year-end examination, the latter promoting cramming. Student responses validated our assumptions, with 97\% (1997) and 89\% (1999), respectively, voting in favour of the incentive scheme (Table 2). In virtually all respects, this reward system served to alleviate some of the reported difficulties (cramming, stress, poor time management) experienced during the year [12], all factors experienced by students in a traditional curriculum [14-18]. By doing so, the reward system appeared to have inherent benefits, as is reflected in some student responses to the principle of obtaining extra marks - promoted consistent and hard work; built confidence and prevented year-end stress and cramming. The latter should be prevented at all costs, as it promotes surface learning [8]. These reasons offered by students in favour of the incentive will undoubtedly be conducive to their adopting more meaningful learning approaches, and provides some evidence to support Knapper's (1995) belief that learning is greatly encouraged if it is rewarded [4].

There is no doubt that the conceptions of learning students hold will influence the approaches they adopt with respect to learning, which will significantly impact on their academic success and on the quality of knowledge they come to possess $[3,11]$. Whether students become surface, deep or strategic learners while at university will depend on individual student qualities and conceptions of learning, which will be influenced by the type of motivation (intrinsic $v s$. extrinsic), the ambiance of the academic environment in which students find themselves and the curriculum they experience $[3,5,10]$. Curricula overloaded with content and assessment, as is found in traditional medical schools such as ours, often result in severely stressed individuals (perceived medical school stress - PMSS - [19]). Furthermore, Eizenberg (1988) warns that sheer volume will discourage students from adopting deep, holistic approaches to learning, making deep learners become surface learners [9]. In these situations, students spend most of their year concerned with failing rather than reflecting on their experiences $[7,12,14]$.

A number of the 1999 second year students, including some of the high-achievers, complained of too little time between tests. This would have prevented them from reflecting on what they were learning and how this might impact on their lives [12]. Thus, for most students in such a curriculum, the only option available is to adopt coping strategies, which more often than not translates into rote learning and memorisation (surface learning and reproductive conceptions of learning). Newble and Entwistle (1986) believe that under such pressure, even deep learners, who usually come to terms with new information by understanding and making personal meaning of the experience, may become surface learners [3]. Since assessment drives learning [1,20,21], we need to ensure that our assessment influences learning positively and does not become an overriding negative influence.

The importance of assessment in influencing student learning cannot be under-estimated [3,10]. Knapper (1995) is of the opinion that assessment is possibly the most important influence on student learning processes and outcomes [4]. So important is assessment on learning that Ramsden (1992) lists "appropriate assessment" as one of his six principles of effective teaching in higher education [22]. Examination questions that do not encourage understanding, give students the message that surface approaches will be rewarded [3,23]. The opposite also holds true. If students anticipate that test questions require understanding, then they will be encouraged to adopt a deep approach [3]. In the present study, where the UCTs emphasize the practical (i.e. tissue identification) and applied (i.e. relating structure to function) aspects of and integrated approach (i.e. with Biochemistry and Physiology) to Histology, the outcomes we expect do not promote memorisation. Students need to develop individual approaches to come to terms with Histology, constructing their own mental images of structures which allows them to differentiate one tissue from another. We encourage students to do this by relating structure to function, hoping they will integrate Biochemistry and Physiology with Histology. Rote learning and memorisation will not allow a student to pass. As educators, we therefore believe that in the type of assessment we use, the student is encouraged to adopt a deep approach to learning. It is only when each student comes to terms with the material on a personal level, that he/ she will truly be able to understand it. While the study did not ascertain from students their learning approaches (a difficult task, as many students are probably not 
able to define their strategies), it might be possible, based on the expected, advertised course objectives (i.e. integrated; applied, functional Histology) necessary to achieve the outcome (i.e. understanding), to provide indirect evidence for student adopting appropriate learning approaches. Without a deep understanding of the course material, it would be virtually impossible for a student to achieve a $70 \%$ average. In excess of $40 \%$ of each year group of students was able to achieve the bonus (Table 2), which would suggest that these students had adopted a deep learning approach. Other indirect evidence to support this assumption may be provided by the conceptions of learning some of these students hold [24]. As part of the extensive survey in 1997, the conceptions of learning [11] held by second year students were canvassed in an attempt to relate these to their academic abilities. Not surprisingly, those students achieving above $60 \%$ were able to express more transformative conceptions of learning, but all students did express the conception that they learnt for understanding [24].

One might argue, however, that some students use the bonus system strategically to enhance the scores they obtain for other second year subjects. If this is true, as a number of student comments indicated, it would not be an unintended consequence on the part of the staff. Since University and Faculty regulations require that students write the year-end examinations, alternative methods were sought to reward consistent and good achievement. In this regard. Histology staff members were satisfied that if students had achieved an overall year mark of $70 \%$, they had come to terms with the level we expected of them (i.e. understanding by developing their own cognitive structures). The bonus system therefore enabled students who scored high marks during the year in Histology to concentrate on subjects that may be causing them problems, e.g. Anatomy and its associated content volume [12]. The term, "strategic learner" in the Newble and Entwistle (1986) sense, does not apply in this instance [3]. Such students are those who will apply any means to obtain high grades, which might involve spotting for exams or attempting to make a good impression on those who they believe might influence their final grades. Neither of these options is possible in preparing for Histology tests. In Entwistle's (1997) definition of a strategic learning approach, i.e. putting constant effort, managing time and effort effectively, might be perceived as being a strategic, organisational approach (Table 1) [8]. It is inevitable that students in the present study will have used the bonus system strategically, allowing them more appropriate time management skills so that hopefully, they were able to adopt more effective learning approaches with regard to other subjects (i.e. less cramming). According to Newble and Entwistle (1986), strategic learners might also not have an understanding of the material they are studying [3]. We are, however, confident that this is not the case in Histology since we assess for understanding (i.e. assessing intended outcomes). An average of $70 \%$ cannot be achieved without an understanding of the subject material.

The bonus system, by providing the incentive to gain extra marks, appears to have motivated students to work harder and consistently. We remain convinced that because of the nature of the learning task in Histology, the approaches students adopt allow them to understand what they are learning. Failure to do so will result in students not passing the course, as the theory, where rote learning and memorisation might be possible, comprises only about $40 \%$ of the assessment. One might, however, argue that this reward system serves as an extrinsic motivating factor, while ideally students should be intrinsically motivated to learn (i.e. Entwistle's (1997) deep approach to learning [8]). Comments from students such as "makes you want to do your best" and "makes one strive to obtain high marks " seem to indicate that what might at first glance be perceived to be an external motivating factor may, for some, has become internalised, as they saw the bonus as an attainable goal. The hope and confidence this gave them when preparing for the exams as well as the comments by some that it made them extend themselves and that they knew what they understood in Histology, can only be viewed in a positive light in terms of motivating students (i.e. promoting the positive, by rewarding rather than sentencing students). One would hope that students might perhaps use this experience positively such that it impacts on their approach to learning in the other subjects studied. If they have learned to integrate Histology with the other preclinical medical subjects, then presumably a proportion of them will use the Histology they have mastered to understand Physiology and Biochemistry.

While many authors have commented on the impact of assessment on student learning largely from a negative perspective $[3,4]$, there are others who believe that if used appropriately, it can become a valuable teaching and learning tool $[1,2,13,20,21]$. To this end, Gipps (1994) is of the opinion that assessment should have higher profile roles than those traditionally associated with norm-reference testing [1]. Included would be its role in supporting teaching and learning, providing information about pupils, teachers and schools, as a selection and certificating device and driving curriculum teaching. In that author's opinion, the psychometric model, which has for decades underpinned assessment theory, is no longer adequate. A paradigm shift is necessary in order for assessment to be more 'authentic', which Woods (1986) and Gipps (1994) refers to as educational assessment $[1,13]$. This form of assessment, 
which attempts to match the learning with the intended outcomes, has several advantages over the traditional view of assessment (Table 5), some of which our assessment in Histology possibly achieves. To this end, students in our course have been asked to raise the level of their achievement (from the average 50\% to 70\%), which requires them to extend themselves beyond what they would normally be satisfied with. The comments of some students clearly indicate that they did indeed extend themselves (Table 4). Each student therefore becomes an individual striving against himself towards a new attainable goal. For this, students are rewarded which is beneficial in terms of their psychological well-being and their motivation to learn and achieve.

Table 5: Some advantages of educational assessment (extracted from Gipps, 1994).

- Deals with an individual's achievement relative to himself than to others

- Tries to test competence rather than intelligence

- Attempts to look for 'best' rather than 'typical' performance

- Views assessment from a constructivist perspective, seeking to help rather than sentence the student

- Takes place in relatively uncontrolled conditions

- Is most effective when rules/regulations that characterise standardised testing are relaxed

If we use assessment in this way and if we are sure that our intended outcomes are met by the assessment, then Gipps (1994) is correct that assessment can become a powerful teaching and learning instrument [1]. We must, however, heed the warning of Race (1997), because in reality, this is where most of us find ourselves: "Moreover, we must ensure that learning is not simply assessmentdriven. It can be argued that presently we have too much assessment, but that neither the quality nor the diversity is right. Students are highly intelligent people; if we confront them with a game where learning is linked to a rigid and monotonous diet of assessment, they will learn accordingly to the rules of the game. To improve their learning, we need to improve our game "[20]. We believe that in rewarding students for their efforts (which Knapper (1995) tells us impacts positively on student learning [4]) in what we deem to be 'authentic' (i.e. tests competence; best performance) assessment (within the constraints of the traditional medical curriculum), we may have contributed to engendering an appropriate and effective learning ethic amongst our students. Considering the stress associated with the current second year of medical studies at the University of Natal $[12,14]$, the bonus system is likely to be one of the few positive experiences for students during these early preclinical years. The new PBL curriculum implemented in the Faculty in
January 2001 will contribute considerably to the alleviation of many of the difficulties (including over-assessment) students are currently experiencing while the traditional curriculum runs its course.

\section{Conclusions}

The bonus system in Histology was initially implemented to alleviate some of the stress many students in the traditional curriculum suffer, particularly in relation to volume overload and excessive assessment in the second year of study. In evaluating its acceptance by students, some of their comments indicate that this incentive might have additional benefits (e.g. promoting continuous effort, providing students with confidence for the other exams; allowing students to extend themselves to a higher level of achievement than they would normally be satisfied with), some of which were not anticipated. While this study relates to assessment in Histology, the principle of offering students an incentive for consistent and excellent performance, provided one is certain that the assessment measures the course outcomes, is applicable across disciplines. The positive response of students in the present study to an incentive might encourage other educators to re-evaluate their assessment procedures, particularly where there might be rigid rules in place with regard to the frequency and scheduling of examinations. If assessment drives learning, and if the learning is rewarded by the assessment, clearly, students should then benefit.

Although the study did not ascertain student approaches to learning (which would be a valuable follow-up), the favourable response of students to the incentive, their encouraging comments which suggest a positive attitude to learning and the knowledge that our assessment measures the expected outcomes of the course, provides indirect evidence of its beneficial effects on student learning. Rote learning and memorisation would not be sufficient for a student to obtain the $70 \%$ average. Since in excess of $40 \%$ of students were able to obtain the bonus, one might argue that this provides further indirect evidence that a large proportion of the students might be practicing the appropriate learning approaches. At worst, these approaches would be strategic and at best, they would be deep approaches. For those who failed to obtain the bonus, the incentive offered had apparently improved their attitude to their studies and encouraged a positive work ethic, which one hopes extended beyond their learning in Histology. Since assessment is generally used summatively, one must be satisfied that it drives the appropriate learning. Just as we have looked at some aspects of the possible impact of our assessment methods on student learning, such an exercise should part of quality assurance and curriculum evaluation in every course. 


\section{Conflicting interests}

None

\section{Acknowledgements}

The author wishes to thank the 1997 and 1999 second year students of the Nelson R. Mandela School of Medicine for agreeing to be part of this evaluation.

\section{References}

I. Gipps CV: Beyond Testing: Towards a Theory. London, Faber Press 1994

2. Cohen-Schotanus J: Student assessment and examination rules. Med Teacher 1999, 21:318-321

3. Newble DI, Entwistle NJ: Learning analysis and approaches: Implications for medical education. Med Edu 1986, 20:162-175

4. Knapper CK: Understanding student learning: Implications for instructional practice. In: Teaching Improvement Practices. Successful Strategies for Higher Education, MA, Anker Publishing Company) I 9955875

5. Hounsell D: Understanding teaching and teaching for understanding. In: The Experience of Learning. Implications for Teaching and Studying in Higher Education (Edited by Marton F, Hounsell D, Entwistle N. Edinburgh, Scottish Academic Press 1997238-257

6. Bligh J: Learning by example. Med Edu 1999, 33:234-235

7. Stiernborg M, Bandaranayake RC: Medical students approaches to studying. Med Teacher 1996, 18:229-236

8. Entwistle N: Contrasting Perspectives on Learning. In: The Experience of Learning. Implications for Teaching and Studying in Higher Education (Edited by Marton F, Hounsell D, Entwistle N) Edinburgh, Scottish Academic Press 19973-22

9. Eizenberg N: Approaches to learning Anatomy: Developing a programme for preclinical medical students. In: Improving Learning - New Perspectives (Edited by Ramsden P) London, Kogan Press 1988178-198

10. Ramsden P: The Context of Learning in Academic Departments. In: The Experience of Learning. Implications for Teaching and Studying in Higher Education (Edited by Marton F, Hounsell D, Entwistle N) Edinburgh, Scottish Academic Press 19971 98-216

II. Marton F, Dall'alba G, Beaty E: Conceptions of learning. Int J Edu Res 1993, 19:277-300

12. McLean M: Student perceptions of their first and second year experiences of medical studies at the University of Natal. MEd Thesis, University of Natal, Durban, South Africa 2000

13. Wood R: The agenda for educational assessment. In: Assessing Educational Achievement (Edited by Nuttall D) London, Falmer Press 1986

14. Olmesdahl PJ: The establishment of student needs: an important internal factor affecting course outcome. Med Teacher 1999, 21:174-179

15. McManus IC: How will medical education change? Lancet I99I, 337:519-1521

16. Buckley EG: Basic medical education in transition. Med Edu 1993, 27:113-115

17. Stewart SM, et al: Predicting stress in first year medical students: a longitudinal study. Med Ed 1997, 31:163-168

18. Stewart SM, et al: A prospective analysis of stress and academic performance in the first two years of medical school. Med Edu 1999, 33:243-250

19. Vitaliano PP, et al: Perceived stress in medical school: resistors, persistors, adaptors and maladalptors. Soc Sci Med 1989, 28: $1321-1329$

20. Race P: 1997 [http://www.lgu.ac.uk:80//deliberations/assessment/artof.html]

21. van der Vleuten CPM: A paradigm shift in education: How to proceed with assessment? Proceedings of the 9th International Ottawa Conference, Cape Town, South Africa, 2000152

22. Ramsden P: Learning to Teach in Higher Education. London, Kogan Press, 1992

23. Trigwell K, Sleet R: Improving the relationship between assessment results and student understanding. Assess \& Eval Higher Edu 1990, 15:190-197

24. McLean M: Can we relate conceptions of learning to student academic achievement? Teaching in Higher Education 200 I, 6:399413

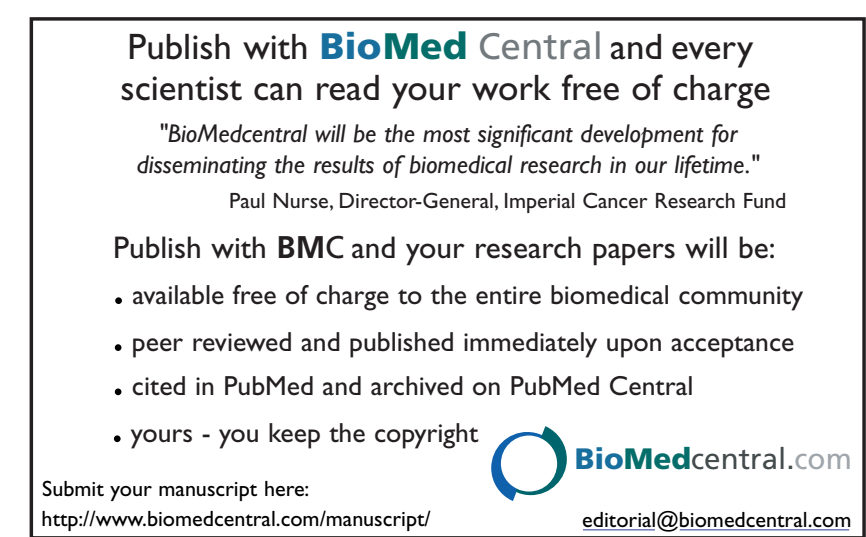

